\title{
Justiça como igualdade? A percepção da elite e do povo brasileiro
}

CELI SCALON*

\section{Apresentação}

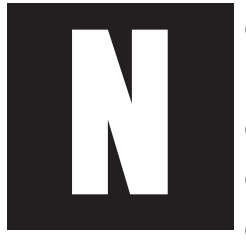

esse artigo, buscamos discutir a visão da elite brasileira sobre desigualdade e justiça social, em contraposição aos demais estratos da população, tendo como base a análise dos dados do survey sobre atitudes e opinião em relação às desigualdades no Brasil. Essa pesquisa foi realizada em 2000 como parte do International Social Survey Programme (ISSP), ${ }^{1}$ e seu objetivo foi captar valores de igualdade e justiça distributiva, bem como percepções sobre os critérios de estratificação vigentes em nossa sociedade. Os temas aqui levantados foram, em grande medida, abordados para o conjunto da população brasileira em trabalhos anteriores (SCALON, 2004; SCALON; CANO, 2006).

Para a análise das questões sociais no Brasil, devemos levar em conta que o país tem, nas desigualdades, sua principal característica, sendo necessário compreender as circunstâncias em que elas surgem e se reproduzem historicamente. Essa situação enseja um debate a respeito das condições necessárias para que as oportunidades sejam de fato iguais e a busca

\footnotetext{
* Professora Titular da UFRJ - Pesquisadora CNPq. Brasil.

1 O ISSP é um programa de colaboração entre países que têm como objetivo realizar surveys sobre tópicos relevantes na área de Ciências Sociais. Nesse sentido, visa promover análises comparativas, integrando uma perspectiva internacional e intercultural aos estudos nacionais. A cada ano, um tópico é escolhido, e um questionário comum é aplicado nos 38 países-membros. Durante cinco anos, fui coordenadora desse programa no IUPERJ.
} 
de respostas para algumas questões cruciais: quais os limites toleráveis das desigualdades? As desigualdades sociais são um problema para a sociedade brasileira? Qual o papel atribuído ao Estado e à própria sociedade no combate às desigualdades sociais? Quais as alternativas para combatê-las?

Neste trabalho, enfocamos as opiniões e valores da elite vis-à-vis os demais grupos da população brasileira. Essa classificação envolve importantes e polêmicas definições conceituais. Entre as várias possibilidades de identificação dos grupos, consideramos como "elite" os 10\% mais "ricos" dos entrevistados, ou seja, o decil que reportou maior renda familiar per capita. A opção por adotar a renda familiar deve-se ao fato de, nos estudos sobre classe econômica, consideramos a família como unidade de análise, uma vez que, em princípio, todos os membros da unidade familiar compartilham do mesmo status e prestígio, bem como das redes e dos recursos. Essa é a razão para se compreender a mobilidade social como um mecanismo de transmissão e herança, que passa pela origem determinada pela classe da família à qual o indivíduo pertence.

A maior parte dos estudos sobre estratificação, em especial sobre mobilidade de classes, adota como indicador de origem social a classe do pai e, como de destino, somente a classe social dos homens. $\mathrm{O}$ argumento é que a classe social de um membro da família determina a classe social de todos os componentes daquela unidade familiar. A opção pelos homens dáse porque estes têm maior inserção e permanência no mercado ocupacional, enquanto as mulheres obedecem a oscilações no ciclo de vida. Mas existem controvérsias em torno dessa opção. Vários pesquisadores preferem incorporar a chamada joint classification como classe de destino, na qual se considera tanto o marido como a esposa, quando se trata de uma família nuclear. Além disso, alguns preferem utilizar como categoria de origem a classe do pai e a da mãe, quando essa informação está disponível. Mas, seja qual for a opção de classificação, todos reconhecem a família como a principal 
unidade de análise (GOLDHORPE, 1983; SORENSEN, 1994; MARSHALL et al., 1995).

Num sentido estrito, os $10 \%$ mais ricos da população não têm uma renda tão alta que os classifique como "elite", mas podem ser classificados como "elite" num sentido relacional. Isso porque o último decil de renda da população está em posição privilegiada em relação aos demais decis. Uma vez que abordamos uma perspectiva que se refere aos valores e percepções construídos por meio das relações sociais, é o sentido relacional que, de fato, nos interessa.

A Sociologia brasileira tem, tradicionalmente, analisado a estrutura social a partir de sua configuração mais objetiva, ou seja, mediante estudos sobre seus aspectos demográficos, da mensuração de diferenças em termos de salário, nível educacional e acesso a bens e serviços, entre outros. Contudo, para conhecer em profundidade os mecanismos de manutenção da ordem social vigente, mesmo diante dos elevados índices de desigualdade vivenciados, é indispensável que, ao lado do exame dos fatores objetivos, seja realizada uma análise dos aspectos subjetivos, de atitude e percepção, da população brasileira.

O survey sobre desigualdades teve cobertura nacional, com duas mil entrevistas, realizadas em 195 municípios, incluindo áreas urbanas e rurais. A amostra é representativa da população brasileira com idade igual ou superior a 18 anos. O critério de seleção foi probabilístico até o nível domiciliar, e, para a seleção dos entrevistados, foram adotadas cotas de sexo, idade, escolaridade e renda. A amostragem foi realizada em três estágios: o primeiro correspondeu à seleção dos municípios; o segundo, ao sorteio dos setores censitários nos municípios já identificados; o terceiro, à seleção dos respondentes mediante cotas proporcionais de acordo com as variáveis já citadas. O número de entrevistas em cada estado, a seleção dos municípios e a definição das cotas foram determinados pelos dados do Censo Populacional e da Pesquisa Nacional por Amostra de Domicílio (PNAD). 
No Brasil, ainda não havia sido produzida uma pesquisa que permitisse conhecer-se como a população percebe e avalia o quadro social em que está inserida, o que deixava algumas questões relevantes sem resposta, como, por exemplo: Como pessoas comuns visualizam a composição de classe de sua sociedade, e como elas posicionam a si mesmas e aos outros nessa imagem? (EVANS; KELLEY; KOLOSI, 1992).

Essa pesquisa visou preencher, ainda que parcialmente, a ausência de informações sobre aspectos subjetivos das desigualdades, retratando a visão dos brasileiros acerca dos diferentes fatores que contribuem para a manutenção ou superação destas. Dessa forma, visou identificar as divisões na estrutura social e na cultura política que produzem variações nas opiniões e valores em relação à igualdade social, permitindo verificar até que ponto é possível apontarem-se conexões entre as posições social e ideológica do indivíduo e sua atitude perante a igualdade e a justiça sociais.

Neste artigo, examinamos as principais dimensões suscitadas pelo survey, comparando as divergências e convergências entre atitudes e opiniões da elite e do povo brasileiro em geral sobre algumas questões abordadas no questionário que julgamos relevantes para a compreensão dos valores e percepções vinculados à idéia de igualdade e justiça. Entre elas, destacam-se: qual o tamanho aceitável da disparidade de renda? Como o desenho da estrutura social e a configuração das classes são reconhecidos? Quais os critérios que devem prevalecer para a remuneração dos agentes? Quais os principais problemas do País? Por último, observamos as alternativas de combate à desigualdade e a quem se atribui a responsabilidade por essa tarefa. $\mathrm{O}$ resultado do estudo permite identificar os pontos de encontro e de desencontro, as percepções, crenças e valores da elite e do povo que, salvo melhor juízo, têm posições sociais bastante distantes, considerando a extrema desigualdade presente na sociedade brasileira.

Muito se tem falado sobre as desigualdades sociais no Brasil, analisando-se, basicamente, suas dimensões objetivas, medidas por intermédio de 
variáveis relativas a características adquiridas da população, tais como renda, ocupação e escolaridade, entre outras, e também a características atribuídas, como sexo, cor/raça, idade etc. Contudo, pouco ou nada se sabe da percepção que a população brasileira tem das desigualdades. Será que os brasileiros vêem o Brasil como um país desigual? E, se o vêem, onde localizam as desigualdades? Como as interpretam e reinterpretam em suas vidas cotidianas? Como se reconhecem ou reconhecem os demais nesse contexto? Quais os principais problemas sociais que afligem a elite e o povo e qual a fórmula apontada para solucioná-los?

As opiniões e percepções sobre as desigualdades variam de acordo com o situs de onde o indivíduo observa e responde. Dessa forma, é sempre esperado que pessoas de diferentes idades, regiões, classes sociais, gênero, escolaridade, raça etc. tenham percepções distintas. Mas, como nosso objetivo é avaliar semelhanças e diferenças na percepção da elite e do povo, vamos nos concentrar somente nesses dois grupos. Além disso, os dados não permitiriam uma análise mais detalhada de diferenças entre os vários grupos sociais. Também tivemos o cuidado de não cair na tentação de confrontar percepções com dimensões objetivamente mensuráveis a fim de confirmar ou falsear as percepções dos indivíduos, o que poderia ser interpretado como um ajuizamento das representações dos respondentes.

Não há, neste trabalho, a pretensão de respondermos a todas essas questões, mas explorar alguns temas abordados no survey. Nossa meta é apreender valores e percepções sobre as desigualdades e as possíveis convergências e divergências entre esses valores e percepções expressos pela elite e pelo povo. A igualdade é, aqui, entendida como critério último de justiça social, no sentido rawlsiano (RAWLS, 1971).

\section{Somos uma sociedade desigual?}

É inevitável pensar que a primeira questão formulada num survey sobre desigualdades devesse mensurar, de alguma forma, se a sociedade bra- 
sileira considera-se desigual ou não. No entanto, uma pergunta tão direta tenderia a mostrar pouca variabilidade, uma vez que a existência de desigualdades sociais está presente no discurso geral, assim como a necessidade de combater a pobreza e a fome. A pergunta mais próxima a essa para se medir a percepção sobre a existência e extensão das desigualdades no Brasil consiste no item no qual os respondentes deveriam dizer se concordavam ou não com a seguinte afirmação: No Brasil, as diferenças de renda são muito grandes. Na elite, $89 \%$ concordaram totalmente, e 7,5\% concordaram em parte, ou seja, 96,5\% concordaram com essa afirmação. O que estamos aqui denominando "povo" inclui 85\% que concorda totalmente, e aproximadamente $11 \%$ que concorda em parte.

Nesse quesito, elite e povo demonstraram uma enorme convergência de opinião, o que é facilmente explicável, uma vez que as desigualdades no Brasil são explicitadas e, freqüentemente, aludidas em discursos veiculados na mídia. Dessa maneira, a concordância com a afirmativa de que existe grande desigualdade de renda pode ser apenas uma repetição de algo que tem sido constantemente exposto no discurso público, vinculado à ampla propagação do ideal moderno de justiça social, presente mesmo nas situações de forte legitimação das desigualdades existentes. Além disso, vale chamar atenção para o fato de que o discurso em defesa da igualdade e a aceitação de elevados níveis de desigualdade não são necessariamente incompatíveis. Até porque existe uma distância entre as dimensões cognitiva e normativa na avaliação das desigualdades.

Uma indicação da dificuldade encontrada pelos indivíduos em realizar um descolamento da vivência cotidiana em direção a um horizonte normativo pode ser encontrada na análise do item do questionário em que uma lista de ocupações, com diferentes níveis de status e prestígio, foi apresentada ao entrevistado para que indicasse quanto deveria ganhar o profissional de cada uma delas. O Gráfico 1 inclui as diferenças entre as médias salariais de 
cada ocupação, tomando como base a ocupação apontada como a que deveria receber o menor salário, ${ }^{2}$ segundo a opinião dos dois grupos, elite e povo.

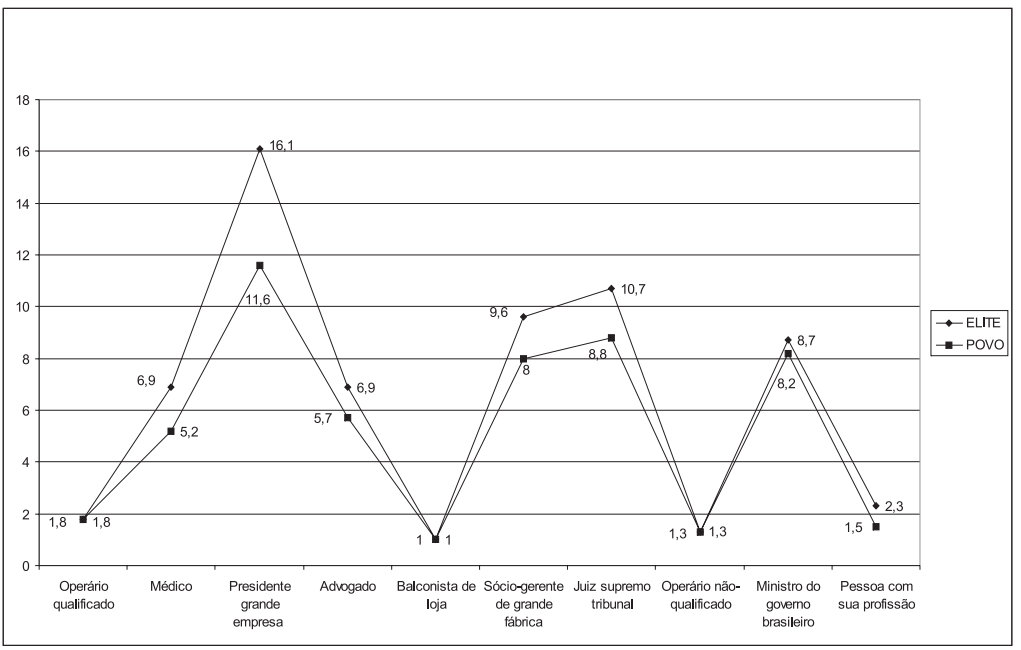

Gráfico 1 - Médias de salários que as ocupações deveriam receber segundo elite e povo.

Fonte: ISSP 2000.

A elite tendeu a conferir valores mais elevados para os salários das ocupações de mais prestígio, em comparação aos valores atribuídos a essas mesmas ocupações pelo povo. Devemos lembrar que estamos tratando aqui dos valores médios relativos, uma vez que não apresentamos as mé-

2 A partir da pergunta Quanto deveria receber um (nome da ocupação)? foi calculada a média dos valores atribuídos pelo respondente para as ocupações. A ocupação que obteve menor valor salarial em média, o que variou de acordo com o país, foi tomada como o denominador para o cálculo da divisão entre as ocupações. Dessa forma, a ocupação base, isto é, a que foi apontada como a que deveria receber o menor rendimento incorpora o valor 1 . 
dias salariais, mas as diferenças entre as médias atribuídas às ocupações em relação à ocupação base, qual seja, balconista de loja.

Essa tendência poderia ser explicada pelo fato de a elite receber salários superiores e, portanto, adotar um parâmetro salarial mais elevado. Porém, observando os valores atribuídos por essa mesma elite para as ocupações menos prestigiosas, verificamos que se igualam aos valores atribuídos pelo povo. Logo, os dados indicam que a elite aceitou uma desigualdade salarial maior do que o povo, e estamos falando do salário que as pessoas nessas ocupações deveriam receber, ou seja, daquele que seria um salário justo. Portanto, a resposta à questão apresentada é, em última instância, uma opção normativa.

O que esses dados indicam é que as diferenças entre as ocupações de maior status e as ocupações de menor status deveriam ser, na concepção da elite, ainda superiores às já expressas na concepção do povo. Importante registrar que os valores atribuídos à ocupação base pela elite e pelo povo foram praticamente idênticos, aproximadamente 855 reais e 849 reais, respectivamente. Portanto, a maior desigualdade relativa nos salários reportada pela elite expressa, em certa medida, também uma desigualdade nos valores absolutos dos rendimentos que deveriam ser pagos às ocupações aqui listadas. O Gráfico 2 permite visualizar melhor essas considerações.

Segundo a elite, o presidente de uma grande empresa deveria ganhar 16 vezes mais que um balconista de loja, a profissão indicada com o menor salário; já para o povo, essa diferença cairia para aproximadamente 12 vezes, o que ainda é uma distância salarial muito grande. Do mesmo modo, os juízes dos supremos tribunais e os sócios-gerentes de grandes fábricas ampliariam sua distância salarial em relação aos demais trabalhadores manuais, se adotarmos como foco a visão da elite. Mesmo médicos e advogados teriam uma diferença salarial maior desde a perspectiva da elite em comparação à do povo. Contudo, povo e elite igualaram-se quando o que estava em discussão eram os salários dos operários, qualificados ou não. 


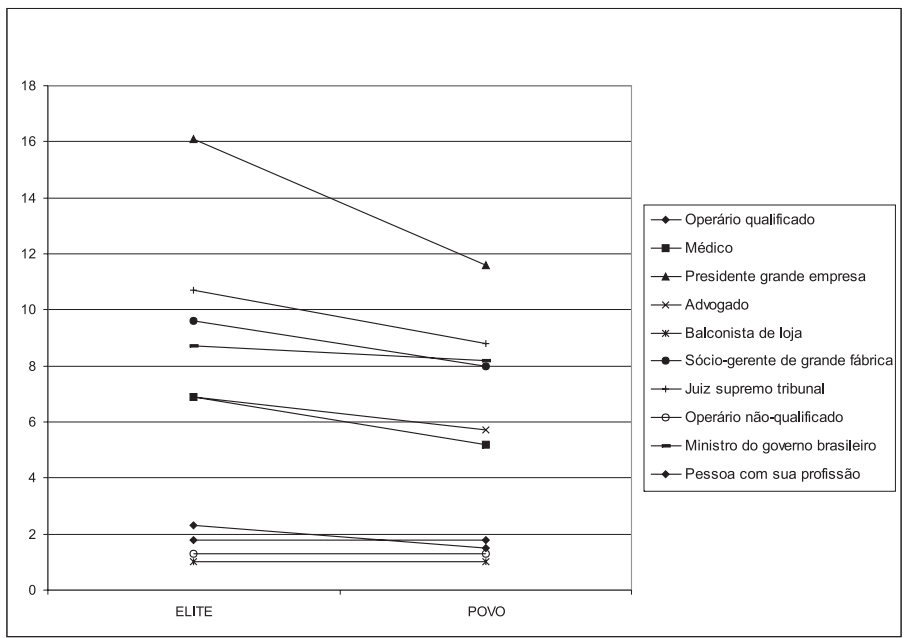

Gráfico 2 - Médias de salários que as ocupações deveriam receber segundo elite e povo.

Fonte: ISSP 2000.

Neste caso, a diferença salarial entre eles e os vendedores de loja, atribuída pela elite e pelo povo, foi exatamente a mesma; operários qualificados deveriam receber 1,8 salários de um balconista, e operários não-qualificados deveriam receber 1,3 salários de um balconista.

Os gráficos apresentados parecem indicar que a elite atribuiu, no nível normativo, disparidades salariais mais extremas entre ocupações com diferentes graus de status e prestígio do que as atribuídas pelo povo. Tal observação pode ser testada com medidas estatísticas mais sumarizadas, por meio do teste de diferença entre médias.

Para proceder a esse teste de hipótese, criamos uma variável construída a partir do desvio-padrão dos salários atribuídos pelo respondente às diferentes ocupações ou grupos de ocupações, tendo sido necessário agrupar algumas ocupações, já que, ao calcular o desvio-padrão para cada uma das 
dez ocupações, foi observado um número elevado de respostas em branco. Dessa forma, optamos por agregar as ocupações com médias salariais semelhantes e com o mesmo fator de uma análise de componentes principais. As categorias então foram reduzidas a sete: a) advogado e médico; b) trabalhador manual não-qualificado; c) presidente de uma grande empresa e gerente de uma grande fábrica; d) juízes do Supremo Tribunal e ministros de Estado; e) trabalhador manual qualificado; f) presidente de empresa; g) balconista de loja. Excluímos a opção "pessoas com sua profissão", por ser essa uma categoria extremamente fluida e de definição incerta, pela própria natureza da construção do item.

O teste de hipótese de diferença entre médias mostrou-se significante a qualquer nível, com uma diferença entre as médias de aproximadamente 1.772 reais. A elite não só apresentou uma média superior à do povo, 5.750 e 3.978 reais, como também registrou um desvio-padrão superior. Esse resultado corrobora a hipótese levantada com base nos dados dos gráficos, qual seja, a de que a elite revelou uma perspectiva normativa que incorporou disparidades salariais maiores do que as atribuídas pelo povo. Em outras palavras, a elite aceitou uma maior desigualdade nos rendimentos que deveriam ser pagos às ocupações com diferentes níveis de status.

\section{Por uma imagem da desigualdade}

Uma das questões mais relevantes nos estudos sobre as desigualdades é a análise da estrutura social. Por meio dela, é possível identificaremse o formato de uma sociedade, pois a maneira como se desenham e articulam as relações entre as classes ou estratos revela, em última instância, uma imagem daquela. Uma sociedade será tanto mais justa e igual quanto melhor for a distribuição dos indivíduos pelos diversos estratos que a estruturam. 
No survey, foram apresentados cinco diagramas aos entrevistados, simulando cinco diferentes tipos de sociedade (ver Apêndice). A partir dessas imagens, foi perguntado: Qual o diagrama que o Sr.(a) acha que melhor descreve o Brasil hoje? $48 \%$ da elite e $42 \%$ do povo indicaram ser o Brasil uma sociedade em forma de pirâmide, representada pelo diagrama Tipo B. Já $41 \%$ da elite e $38 \%$ do povo viram a sociedade brasileira formada por uma pequena elite no topo da pirâmide, poucas pessoas no meio e muitas na base, ou diagrama do Tipo A. Outra vez, é possível afirmar que elite e povo tiveram visões muito semelhantes da estrutura social brasileira, percebendo-a como dividida entre uma pequena elite que ocupa as posições do topo da hierarquia e a grande massa da população compondo sua base.

Contudo, havia o interesse em se conhecer não somente a opinião dos brasileiros de como seria a estrutura social brasileira, mas também avaliar-se sua perspectiva normativa de como deveria ser a estrutura social brasileira. Assim, foi perguntado a seguir: E como o Sr.(a) acha que o Brasil deveria ser? O resultado está no Gráfico 3.

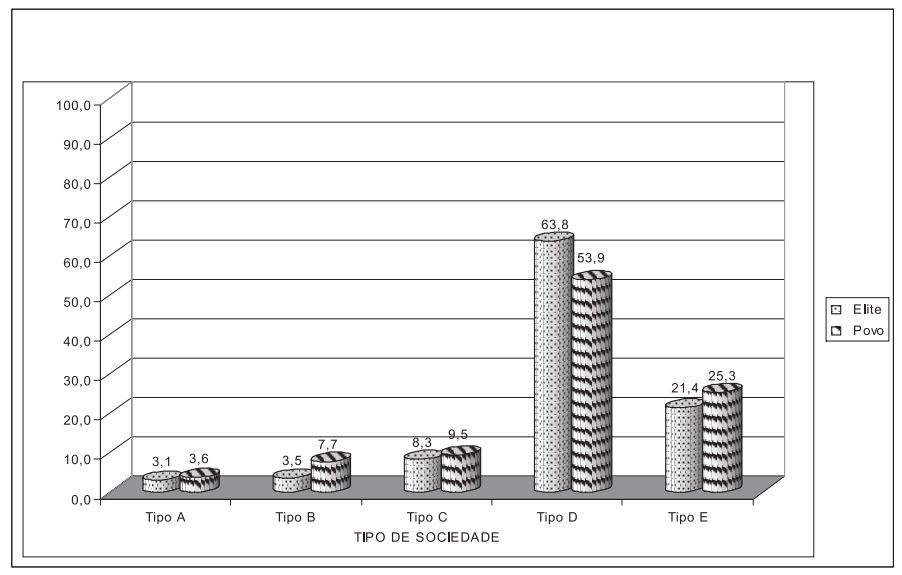

Gráfico 3 - Diagrama que melhor representa como deveria ser a estrutura social brasileira, segundo elite e povo.

Fonte: ISSP 2000. 
Aproximadamente $64 \%$ da elite e $54 \%$ do povo afirmaram que o Brasil deveria se estruturar como uma sociedade do ao Tipo D, ou seja, uma sociedade composta por uma maioria de classe média. Embora esse tipo de estrutura social tenha recebido a adesão de mais da metade do povo, ele teve uma proporção ainda mais representativa na elite, com uma diferença de $10 \%$ entre os dois grupos. Embora a amostra, com número de casos reduzido, possa influenciar na variação dos dados, acreditamos que uma diferença de $10 \%$ tenha relevância e indique tendências. Esse resultado pode estar apontando para uma opinião tipicamente de classe média, uma vez que o que estamos considerando elite é perfeitamente adequável à idéia de uma classe média.

Do mesmo modo, observamos que uma proporção maior do povo (25\%) em relação à elite (21\%) desejava viver numa sociedade do tipo B, com muitas pessoas próximas ao topo e somente alguns poucos próximos à base, ou seja, uma sociedade que tivesse a forma de uma pirâmide invertida, exatamente o contrário da imagem que os brasileiros têm da sociedade em que vivem.

Deve-se notar que os dois tipos de sociedade mais almejados, tipo D e tipo $E$, foram os menos indicados como aqueles que representariam a estrutura social brasileira como ela de fato seria. Essa conclusão revela que, tanto para a elite como para o povo, nossa sociedade ainda está muito distante do modelo que consideraram como o de uma sociedade justa.

Justiça e igualdade: valores traduzíveis?

Uma questão a ser destacada é a "dicotomia" igualdade social e liberdade individual, que contrapõe, de um lado, a defesa dos benefícios sociais, o fortalecimento do Estado de bem-estar e uma política distributiva e, de outro, a meritocracia, o individualismo, as características individuais 
adquiridas e a competitividade. Dessa forma, é interessante averiguar a preferência da elite e do povo em face dessa dicotomia e, dessa forma, verificar se existe variação nas opiniões de acordo com as características dos dois grupos sociais em tela. ${ }^{3}$

Uma dimensão relevante para elucidar essa questão foi o critério de justiça distributiva defendido pelos entrevistados para definir remuneração, considerando-se se deveria prevalecer o grau de escolaridade, a hierarquia das posições de emprego ou a situação familiar. O questionário incluiu quatro itens, cuja importância era relacionada à quantia que cada um deveria receber, e listou alguns fatores, expostos na Tabela 1. Os itens foram os seguintes:

a) tempo de educação e treinamento;

b) exercício de função de chefia ou supervisão;

c) necessidade de sustentar a família; e

d) existência de crianças para criar.

Os dois primeiros itens respeitam, claramente, a características individuais, referentes à ocupação e ao trabalho que os indivíduos desempenham. Os dois últimos aludem às necessidades de manutenção da família, que seriam objeto de compensação e assistência, ou seja, alvo de políticas distributivas.

As proporções registradas na Tabela 1 mostram uma grande convergência entre o povo e a elite acerca do que seria importante para definição da atribuição de renda. Ambos os grupos deram mais peso aos fatores característicos de situações sociais vulneráveis, isto é, referidos às condições de vida e que podem ser, conseqüentemente, alvo de benefícios sociais. Dessa forma, compartilharam opiniões que apontam para a prioridade do social sobre o individual. No entanto, devemos reconhecer que essas ques-

3 Para uma análise dos dados relativos à Espanha, ver Noya e Vallejos (1992). 
Tabela 1 - Importância para definir quanto cada pessoa deve receber, segundo elite e povo.

\begin{tabular}{c|cc|c|c|c|c|c|c|c}
\hline \multirow{2}{*}{ OPINIÃO } & \multicolumn{8}{|c}{ REMUNERAÇÃO DEVE CONSIDERAR } \\
\cline { 2 - 9 } & \multicolumn{2}{|c|}{ Educação/Treinamento } & \multicolumn{2}{c}{ Chefia/Supervisão } & \multicolumn{2}{c}{ Sustentar família } & \multicolumn{2}{c}{ Ter criança } \\
\cline { 2 - 9 } & POVO & ELTE & POVO & ELITE & POVO & ELITE & POVO & ELITE \\
\hline Extremamente importante & 34,6 & 36,0 & 34,0 & 38,2 & 53,1 & 52,9 & 51,9 & 51,5 \\
Muito importante & 45,5 & 41,4 & 40,1 & 36,6 & 32,2 & 32,8 & 32,5 & 30,5 \\
Bastante importante & 15,1 & 15,9 & 19,0 & 18,1 & 11,2 & 9,7 & 11,0 & 12,1 \\
Pouco importante & 4,3 & 6,3 & 6,6 & 6,7 & 2,5 & 4,2 & 3,7 & 4,2 \\
Nada importante & 0,5 & 0,4 & 0,3 & 40,44 & 1,0 & 0,4 & 1,0 & 1,7 \\
Total (\%) & 100 & 100 & 100 & 100 & 100 & 100 & 100 & 100 \\
$N$ & 1524 & 239 & 1523 & 238 & 1540 & 238 & 1534 & 239 \\
\hline
\end{tabular}

Fonte: ISSP 2000.

tões talvez não tenham deixado claro, para o respondente, a dualidade igualdade social/liberdade individual ou, ainda, a escolha entre Estado de bem-estar e competitividade do mercado. O que pode estar em jogo aqui é simplesmente uma perspectiva que volta seu foco para a sobrevivência, o que seria compreensível numa sociedade com elevados níveis de pobreza e privação relativa. Além disso, deve-se considerar que a família e, em especial, os filhos têm uma enorme importância para os brasileiros (ARAÚJO; SCALON, 2005). Tratar-se-ia, portanto, mais de uma perspectiva humanista do que necessariamente igualadora. Mas, atendo-nos aos resultados, podemos concluir que elite e povo aderiram à perspectiva da igualdade. Se isso for fato, precisamos saber quem seria identificado, pelos brasileiros, como responsável pela promoção de bem-estar social, ou seja, no limite, quem pagaria a conta pela distribuição de riqueza.

Ao mesmo tempo, era importante apreender em que medida os indivíduos identificavam a solução de problemas sociais, principalmente a pobreza e a desigualdade, com o papel do Estado. Assim, tentamos avaliar o grau de responsabilidade pelo combate às desigualdades que a elite, por 
um lado, e os demais estratos da população, por outro, atribuíam ao governo, a diferentes atores. Um item do questionário apresentava como possíveis alternativas para essa pergunta: (a) governo; (b) deputados e senadores; (c) empresários; (d) líderes religiosos; (e) trabalhadores; (f) pessoas como o sr.(a).

Tanto elite como povo atribuiram esse encargo quase exclusivamente ao governo, com percentuais de $63 \%$ e $62 \%$ respectivamente. Se somarmos a esse o percentual que incorpora os respondentes que escolheram "deputados e senadores", ampliando assim o leque do que entendemos como poder público, temos $74 \%$ da elite e iguais $74 \%$ do povo. Quando se trata de chamar para si a responsabilidade, observamos parcos $6 \%$ da elite e $4 \%$ do povo.

Fica claro que a cultura política em nosso país envolve o amplo reconhecimento do Estado como o principal ator no combate às desigualdades. Poucos se identificam como capazes de assumirem tal papel. Essa é uma percepção consistente com um contexto histórico em que os direitos civis foram, invariavelmente, incorporados mediante decisões políticas tomadas no âmbito do Estado, sem esquecer os 25 anos da ditadura militar, responsável pela desarticulação de movimentos sociais e políticos. Do mesmo modo, a articulação dos atores em torno de organizações da sociedade civil é, ainda, incipiente no Brasil e data dos anos 1980, apesar da proliferação de entidades que compõem o chamado terceiro setor. Embora considerando que o Estado é, de fato, uma instância fundamental na superação das desigualdades em qualquer sociedade, devemos, também, apontar que o resultado desse item traduz as baixas participação e representação da sociedade e, mais ainda, a dificuldade que os brasileiros têm de se distinguirem como agentes responsáveis e capazes de combater as desigualdades.

Para compreender melhor estas opiniões, era imprescindível observar se o povo e a elite compartilhavam de visões similares ou divergentes sobre 
quais os principais problemas sociais do País e quais soluções deveriam ser buscadas para se combater a desigualdade. Quando perguntados sobre os maiores problemas do País, elite e povo pareceram não compartilhar exatamente das mesmas preocupações. O teste do Chi-quadrado e o Phi revelaram que as diferenças entre os dois grupos eram significativas. A visualização do Gráfico 4 ajuda a desvendar onde eles se desencontraram.

Gráfico 4 - Quais os maiores problemas do Brasil, segundo elite e povo.

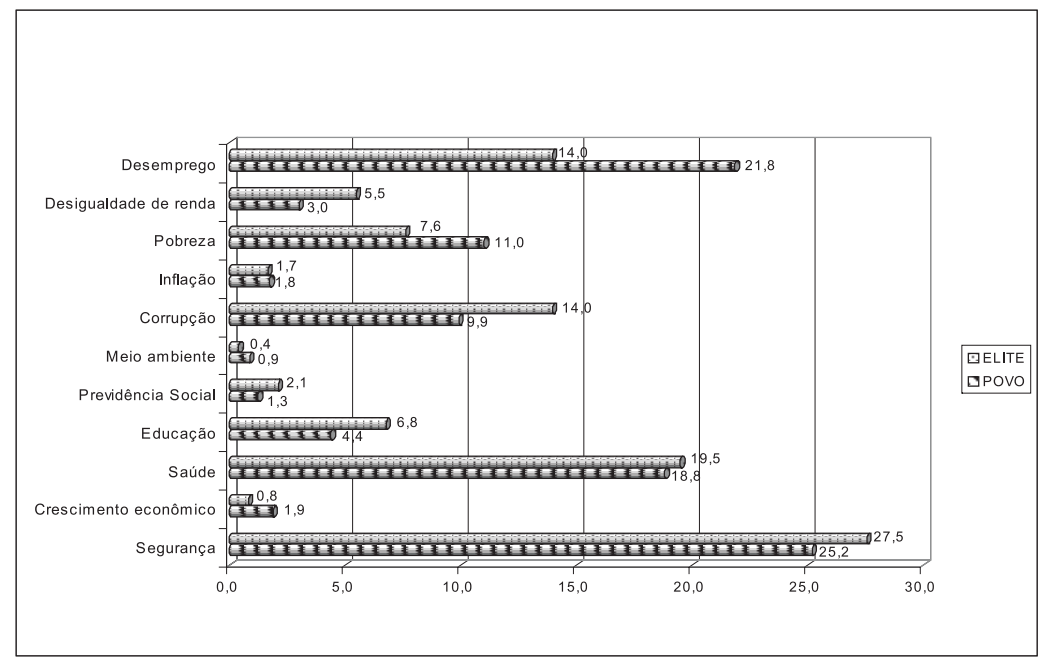

Fonte: ISSP 2000.

Os dados mostram que a falta de segurança é, atualmente, a maior inquietação dos brasileiros e, nesse ponto, concordaram povo e elite. $\mathrm{O}$ problema da saúde teve um alto grau de adesão e, também, consistiu num ponto de convergência entre os dois. Mas houve diferenças nada sutis entre a opinião do povo e da elite sobre o que consistiria o maior problema do País. O povo mostrou-se mais preocupado com o desemprego e a po- 
breza, enquanto a elite angustiava-se com a corrupção. Essa era uma tendência esperada, já que o povo concentra-se na sobrevivência, enquanto a elite focaliza na corrupção um agravante dos demais problemas. Aqui vale a pena recuperar a idéia de Beck (1992), de que a sociedade contemporânea é uma sociedade de pós-escassez:

Nos Estados de bem-estar social do ocidente um duplo processo tem lugar. De um lado, a luta pelo "pão cotidiano" perdeu sua urgência como problema fundamental que obscurecia todo o resto, comparado com a subsistência material na primeira metade do século, e com a ameaça de fome no Terceiro Mundo. Paralelamente, o conhecimento tem difundido que as fontes de riqueza são "poluídas" por crescentes efeitos colaterais perigosos. (BECK, 1992, p. 20).

Beck tem como objetivo mostrar que esses efeitos colaterais constituem riscos, e que o risco tem como principal característica a reflexividade social, um elemento essencial da modernidade, já que é produto da própria modernização. Sua teoria ajuda a explicar por que sociedades afluentes tendem a se preocupar mais com a ecologia e outras questões menos vinculadas à subsistência imediata, enquanto sociedades menos privilegiadas tendem a aceitar os riscos, como efeitos colaterais, em troca da aceleração do processo de modernização.

O que Beck nos oferece é uma forma de compreender as diferenças entre a preocupação da elite e do povo. Tendo ultrapassado o problema de garantia da sobrevivência, ou, nas palavras de Beck, do "pão cotidiano", a elite volta-se para problemas como a corrupção. Na visão da elite, a corrupção é equiparada ao desemprego e supera a pobreza, e se o povo e a elite afastam-se na percepção dos problemas, também se distanciam na opção por alternativas de combate à desigualdade.

O questionário incluiu um item no qual se perguntava sobre quais as políticas mais importantes para combater a desigualdade. Os respondentes 
podiam apontar três categorias de resposta, mas, na Tabela 2, estamos apresentando apenas o que foi apontado como primeira opção. De qualquer modo, a tabela de resposta múltipla registrou uma distribuição idêntica à observada na tabela 2.

Tabela 3 - Políticas mais importantes para combater a desigualdade no Brasil (1ํㅡ opção).

\begin{tabular}{l|c|c}
\hline POLÍTICASMAIS IMPORTANTES & POVO & ELITE \\
\hline Reforma agrária & 30,3 & 22,9 \\
Melhora dos serviços públicos & 40,6 & 44,6 \\
Diminuir ritmo crescimento populacional & 4,0 & 9,1 \\
Privatizar empresas públicas & 1,7 & 2,2 \\
Aumentar impostos mais ricos & 6,8 & 6,5 \\
Trabalhadores participar lucros empresas & 16,7 & 14,7 \\
\hline Total & 100,0 & 100,0 \\
$\mathrm{~N}$ & 1507 & 231 \\
\hline
\end{tabular}

Fonte: ISSP 2000.

Povo e elite apontaram a importância de se melhorarem os serviços públicos, o que indica o desejo por mais investimento do Estado em bemestar social. Contudo, diferenciaram-se na preferência quanto à reforma agrária (esta mais indicada pelo povo) e ao controle populacional (este mais apontado pela elite). Apesar de povo e elite convergirem em suas opiniões sobre o aumento dos impostos para os mais ricos, esse quadro mudou quando estava em foco um item diretamente relacionado ao aumento de impostos. Sem se limitar aos ricos esse aumento e introduzindo-se a idéia de que o valor recolhido seria investido em benefícios sociais, o povo tendeu a aderir mais do que a elite, com 52\% de concordância, total e parcial, enquanto essa proporção foi de $42 \%$ para a elite. É notável que um percentual idêntico da elite, isto é, $42 \%$, tenha discordado totalmente dessa afirmativa, contra $23 \%$ dos demais respondentes. 


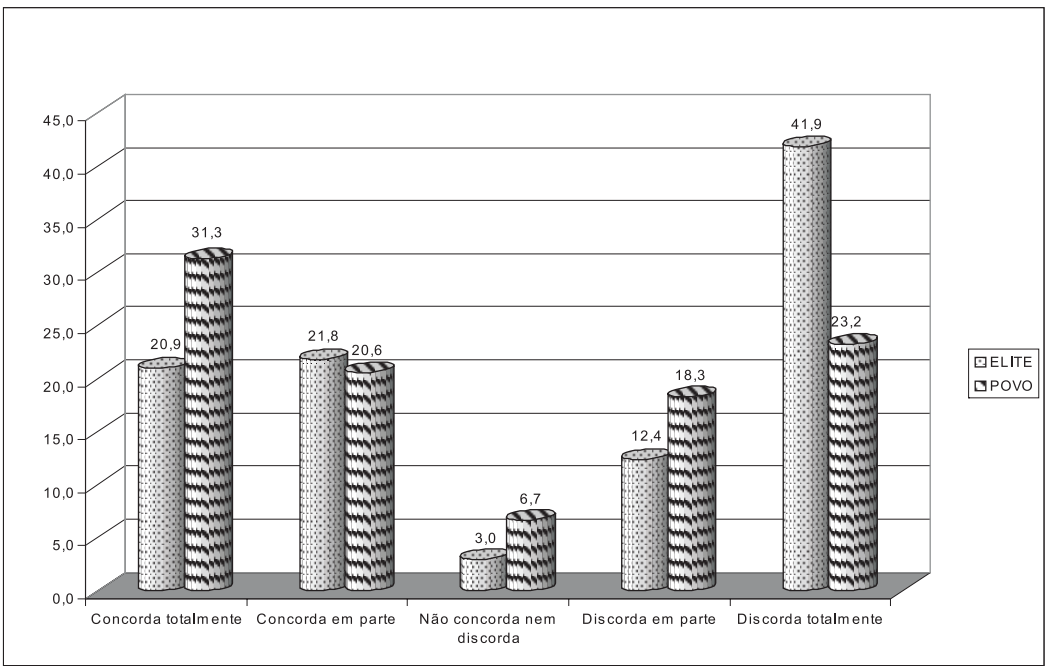

Gráfico 5 - Aumento de impostos pelo governo para investimento em benefícios sociais.

Fonte: ISSP 2000.

\section{A guisa de conclusão}

O objetivo desta análise foi comparar as percepções e opiniões da elite e do povo sobre desigualdades e justiça social. Para tanto, buscamos nos basear nas informações coletadas por meio de survey nacional. Mesmo admitindo a limitação dada pelo formato do instrumento metodológico, que nem sempre permite maior aprofundamento das questões, acreditamos que foi possível, ao longo deste estudo, observar algumas tendências e padrões que revelam alguns traços das percepções e valores da elite e do povo ora compartilhados, ora divergentes.

Não era esperado que elite e povo expressassem perspectivas opostas todo o tempo, tendo já trabalhos anteriores sobre o tema revelado congruências entre as visões de diferentes grupos da sociedade brasileira. A 
conformação de uma cultura compartilhada é fundamental para se produzirem mecanismos de legitimação para as desigualdades e a viabilização da convivência entre níveis de distinções tão elevados e profundos.

Os dados indicaram que tanto a elite como o povo reconhecem a sociedade brasileira como extremamente desigual e desejam viver em uma estrutura social com um desenho mais humano, que incorpore grande parte da população em suas camadas médias. Mas ainda assim, elite e povo conformam-se com elevadas disparidades de renda entre agentes que exercem profissões distintas. Ao atribuir valores para salários que deveriam ser pagos a ocupações com status tão distantes como a de médico e a de operário, os brasileiros reproduzem a desigualdade que vivenciam. A elite, mais ainda que o povo, espelha no nível normativo o que apreende no nível cognitivo: o profundo fosso que separa as rendas. Apesar disso, a elite mostra-se mais cética quanto às possibilidades de recompensa obtida por meio do esforço pessoal ou da inteligência e qualificação, o que traduz, em última instância, o investimento em educação. Esses resultados podem ser visualizados no Gráfico 6.

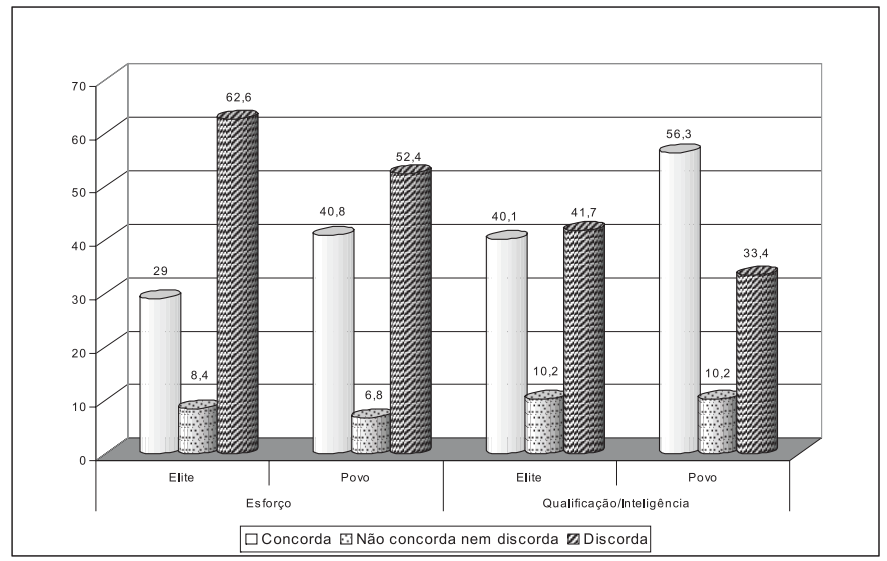

Gráfico 6 - As pessoas são recompensadas por seus esforços, por sua inteligência e qualificações. 
O povo mostrou-se mais confiante nas recompensas obtidas em função de qualidades pessoais, talvez essa uma estratégia de manter a crença na superação de sua condição social. Note que povo e elite apostam mais na educação. De fato, estudos anteriores baseados nesses dados apontaram para o papel relevante que a educação e o treinamento desempenham para a percepção e, também, legitimação dos critérios de estratificação no Brasil. Mas é novo o que surge em nossa análise, confrontando as opiniões da elite e do povo.

Ao atribuir maior disparidade de renda às ocupações e, ao mesmo tempo, acreditar menos nas chances de sucesso via esforço e educação, a elite monta um cenário que, em muito, se assemelha à imagem de uma gaiola de ferro. Isso porque traduz um aprisionamento das classes desprivilegiadas em suas posições e, pior, em posições muito díspares quando comparadas à da própria elite. A elite não só estabelece a distância, como não confia na possibilidade de transpô-la.

A elite também insiste em atribuir ao Estado a solução para as desigualdades, mas não admite o aumento de impostos com vistas à aplicação em benefícios sociais, o que caracterizaria uma clara política de transferência. Ao eleger as políticas de combate às desigualdades, diferencia-se do povo por apontar a diminuição do ritmo de crescimento populacional, enquanto o povo escolhe, em proporção superior à da elite, a reforma agrária. Embora povo e elite indiquem majoritariamente a falta de segurança como um dos problemas mais graves do País, diferenciam-se, sempre guardadas as proporções, ao assinalar a corrupção, no caso da elite, e o desemprego, no caso do povo.

Como vimos, os brasileiros, pertençam ao povo ou a elite, não se reconhecem como os principais atores no combate às desigualdades, mas igualmente concordam com a afirmação de que as pessoas não se unem para acabar com esse problema social, o que foi apontado por $85 \%$ da elite 
e $86 \%$ do povo. Contudo, ainda ficamos por conhecer quem seriam essas pessoas que deveriam se unir para lutar contra esse que é o mais grave problema do Brasil.

Por um lado, a solução passa pelo Estado, que, por sua vez, tem as mãos atadas, pois não deve aumentar impostos para investir em benefícios sociais. Por outro lado, a sociedade não aparece como o principal ator na solução das desigualdades. Os agentes não se reconhecem na posição de combater as disparidades, mesmo afirmando que o fato de não se unirem para combatê-las contribui para sua persistência. Diante de tal cenário, parece não haver saída possível.

Apêndice - Desenhos de estrutura social
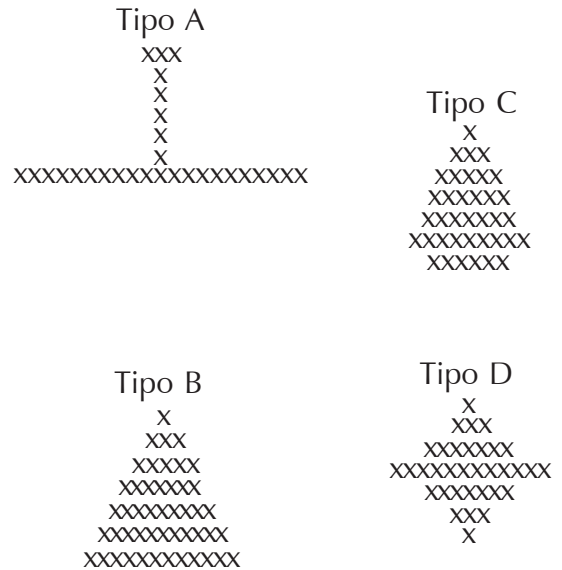

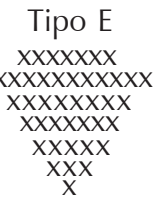




\section{Referências}

ARAÚJO, C. e SCALON, C. Gênero, Família e Trabalho. Rio de Janeiro: FGV. 2005.

BECK, U. Risk society. London: Sage, 1992.

EVANS, M. D. R., KELLEY, Jonathan e KOLOSI, Tamas. - "Images of Class: Comparative Analysis of Public Perceptions in Hungary and Australia". American Sociological Review, no 57, pp. 461-482, 1992.

GOLDTHORPE, J. H. Women and class analysis: in defence of the conventional view. Sociology, v. 17, n. 4, p.465-488, 1983.

MARSHALL, G.; ROBERTS, S.; BURGOYNE, C.; SWIFT, A.; ROUTH, D. Class, gender, and the asymmetry hypothesis. European Sociological Review, v. 11, n. 1, p.1-15, 1995.

ISSP. Survey sobre percepção de desigualdades. International Social Survey Programme - ISSP, 2000.

NOYA, Javier e VALLEJOS, Antonio. Las Actitudes ante la Desigualdad en España. Madrid: CIS, 1992.

RAWLS, J. A theory of justice. Cambridge: Harvard University Press, 1971.

SCALON, C. (Org.). Imagens da desigualdade. Belo Horizonte: UFMG, 2004.

SCALON, C.; CANO, I. The Brazilian way of dealing with inequality. In: COSTA, S. et al. (Org.). The Plurality of Modernity. Mering: Hampp, 2006.

SORENSEN, A. Women, family and class. Annual Review of Sociology, v. 20, p.2747, 1994. 


\section{Resumo}

Os estudos sobre as desigualdades sociais no Brasil concentram-se, em geral, nas dimensões objetivas do fenômeno, como sexo, cor, renda, ocupação e escolaridade. A amplitude do fosso entre ricos e pobres, graças às pesquisas já realizadas, é razoavelmente conhecida, mas pouco se sabe sobre a maneira como os brasileiros vêem essa disparidade. Em 2000, como parte do International Social Survey Programme tentou-se preencher essa lacuna com um survey aplicado a representantes das elites nacionais, entendendo-se por "elites" indivíduos pertencentes ao grupo dos $10 \%$ mais ricos do país. A pesquisa, de abrangência nacional - 2 mil entrevistas em 195 municípios -, buscou revelar diferenças entre as percepções da "elite" e do "povo" acerca da desigualdade. As questões levantadas pelo survey diziam respeito à imagem que os dois grupos têm da sociedade brasileira e da forma como ela está estruturada; as remunerações que seriam adequadas para trabalhadores de diferentes níveis de qualificação; os valores que deveriam prevalecer na distribuição da riqueza do país; os maiores problemas do Brasil; e as estratégias preferenciais de cada grupo para a redução da pobreza, com destaque para o papel do Estado. As respostas revelaram convergências e divergências surpreendentes entre povo e elite. Os dois grupos percebem a extensão das desigualdades sociais no país, mas tendem a defender estratégias distintas para reduzi-las, transferindo a solução das desigualdades ao Estado. Essas aproximações e diferenças de pontos de vista podem oferecer elementos importantes para se compreender os mecanismos de legitimação das desigualdades.

Palavras-chave: desigualdades, justiça, igualdade, percepções sociais, elites.

Recebido: 15/05/2007

Aceite final: 10/06/07 